\title{
Learning through Doing
}

L ast fall many readers of this journal were kind enough to fill out a survey emailed to our individual (as opposed to institutional) subscribers. About 200 people responded to questions about what sections they read, why they value the journal, and what ideas they have for improvement. This was a self-selected group, of course, and their responses cannot represent the views of Ecological Restoration's full readership. However, the survey results indicate that this publication has many long-term subscribers who come from diverse backgrounds, but who value the journal for some similar reasons.

Of the 202 respondents (mainly from the U.S.), over $32 \%$ work in the private sector as consultants, scientists, and managers. Federal, state and local governments employ another $25 \%$ as land managers, planners, and agency scientists. People in academia represent $23 \%$ of survey respondents, while the rest identify themselves as private landowners, volunteers, or people working for non-profit groups.

We asked people to rank $E R$ in the list of similar journals they read and to tell us why. We received 166 comments, with the majority being positive. Specifically, 102 respondents rate the journal as the top one or two they read, and of those, 65 used the words "relevant," "applied," or some form of "practical" to explain why they valued the journal. One respondent wrote, “. . . in Ecological Restoration I continue to find a good balance of sound science grounded in practical experience and/or experimentation." Another stated, "I am a practitioner and scientist. I actually value your journal more as a practitioner and hope you will value this angle." We also received this comment: "I work in the restoration field and it has more applied information than most other journals. It is very important to me because the opportunity it provides to read about what other practioners are doing. It is a great clearinghouse of info and has helped me to improve some of my practices in restoration implementation." Reflecting these sentiments, another respondent stated, "Please remain open to contributions from varied, (i.e., non-professional, non-academic) sources. Making ER just another academic journal would be a real tragedy."

A corollary theme emerging from comments submitted on ways to improve $E R$ was the value of covering diverse

Ecological Restoration Vol. 26, No. 1, 2008

ISSN 1522-4740 E-ISSN 1543-4079

(02008 by the Board of Regents of the University of Wisconsin System. topics related to restoration. I was interested to read, for example, "There is a lot more to restoration than the science. How the public is engaged in restoration, both in creating problems, and then fixing them, and how people relate to the natural world, are the most paramount issues to be exploring." Another person contributed, "You're missing something big if you don't discuss the human dimensions of restoration, and the social and psychological and even spiritual dimensions." In addition, someone commented that the journal should include "more discussion of social processes and participation as to what the goals of restoration should be as a complement to the scientific measurement and assessment of techniques."

In terms of areas of interest, invasive species was by far the topic of greatest concern. Respondents also indicated interest in restoration of grasslands, wetlands, riparian areas and lakes, forests, and deserts and semi-arid lands. Climate change was also a topic of interest as was urban restoration. Several respondents indicated that they wanted to see better coverage of policy developments; one person stated that an understanding of "political context" is critical to doing good work.

I was pleased to read these comments, which help me reflect on the editorial mission of this journal and how Ecological Restoration can best contribute to the practice of restoration around the world. Looking back over past issues and reading comments from long-term readers, I see how the journal provides a forum where different experiences and perspectives are held in mutual respect and regard. This cannot be taken for granted. As areas of practice and investigation become more specialized, we often see inclusive forums disappear. While this specialization is important to scientific and professional development, it can be disconnected from problem-solving. In addition, putting the pieces together again can be expensive. Consider for example, the National Science Foundation's "Dynamics of Coupled Natural and Human Systems" initiative which funds research that enhances "fundamental understanding of the complex interactions within and among natural and human systems." Ecological Restoration makes a contribution by offering a publishing platform for case studies, stories, and other research efforts that celebrate and explore the natural and human as mutually constitutive.

As many readers will note, previous editors Bill Jordan and Dave Egan both emphasized the practice of restoration and the human as well as scientific elements of restoration. Perhaps I might offer some additional thoughts on why an 
emphasis on practice and application is critical for this journal. As a researcher examining "geographies of ideas," that is, where, how, and why ideas and technologies develop, I appreciate how groups of people, sometimes practitioners and scientists working together, have been able to develop brand new technologies, and open up completely new areas of investigation. This emphasizes the "two-way street" between research and application, since research is often informed and guided by the questions and issues raised in practice. Donald Schön, an innovative thinker about the relationship between practice and learning, and author of The Reflective Practitioner in 1983, wrote a great deal about how professionals learn through action — through doing their job. He focused on how a new approach or new way of thinking can develop out of the context of action. Describing a hypothetical (male) practitioner at work, for example, he wrote:

The practitioner allows himself to experience surprise, puzzlement, or confusion in a situation which he finds uncertain or unique. He reflects on the phenomenon before him, and on the prior understandings which have been implicit in his behaviour. He carries out an experiment which serves to generate both a new understanding of the phenomenon and a change in the situation. (Schön 1983, 68)

Thus restoration practice not only brings about change in ecological communities (broadly defined) but generates new understandings of those communities.

We have made some changes in the journal in order to better highlight restoration in practice. We have brought the Restoration Notes section up front and are doubling our efforts to solicit pieces for this section, which is a place for people to share ideas, anecdotes, and small data sets relating to their restoration efforts. This new format also allows us to list Notes titles in the table of contents so that busy people can scan for pieces relevant to them. We are also emphasizing appropriate peer review such that practitioner-authored pieces are reviewed by other practitioners, and that scientific articles are reviewed by colleagues with expertise in that field. I am also seeking to add to our Advisory Board for the journal and am particularly interested in expanding representation from people practicing restoration (please let me know if you are interested).

Another method through which we plan on staying in touch with our diverse readership is to identify several established "correspondents," who will report occasionally about progress, issues, and events in their area. Through a note, editorial, opinion piece, interview or article, for example, correspondents can share information about policies affecting restoration, progress in experimental restoration science, large projects at a biological field station, the restoration industry, new technologies, international developments, or other areas of interest to the restoration community.

To assist me in moving ahead with all of these ideas, I'm pleased to announce our new associate editor, Chris Reyes. After posting the job notice last fall, we received over 50 applications, many from very accomplished editors. There were far fewer applicants who also offered an advanced degree in ecology and on-the-ground restoration experience. Chris Reyes has both of those, and as some of you who have worked with her know, she can edit. I am looking forward to working with her, and with many of you, in 2008. As always, your comments and thoughts on this editorial or the pieces in the journal are most welcome.

Mrill Ingram

Editor 